\title{
The Relationship between Perceived Parental Control and Internet Addiction: A Cross-sectional study among Adolescents
}

\author{
Levent Cetinkaya \\ Canakkale Onsekiz Mart University, Turkey
}

Submitted: 23.07 .2018

Accepted: 09.10.2018

Published: 15.01 .2019

\begin{abstract}
This study aimed to investigate the relationship between parental psychological and behavioral control which the adolescents perceived from their parents and internet addiction. It employed relational survey model and was carried out with the participation of a total of 356 students (female $=205$, male $=151$ ) aged $14-18$. Correlation and regression analyses were utilized to determine the level and direction of the relationship between their perceived parental psychological and behavioral control, and internet addiction. The results yielded a positive, medium-level and meaningful relation between them. It was found that parental psychological control explained nearly $18 \%$ of the total variance in internet addiction and mothers are perceived as significantly more psychologically controlling in internet addiction than fathers. Also, the relationship between parental behavioral control and the level of adolescents' internet addiction was found negative and non-significant. Consequently, it was noted that perceived parental psychological control was effective in adolescents' internet addiction tendencies, whereas behavioral control did not produce such effect.
\end{abstract}

Keywords: Internet addiction; Psychological control; Behavioral control; Parental control

\section{Introduction}

Parents often could attempt to guard or protect their children in order to raise them within the domestic rules and sociocultural norms. The commonly followed strategies (prescription, restriction) could lead to both positive (explanation, discussion) and negative (disagreement, criticism) consequences (Austin, 1990). In the related literature, there are a number of research findings towards the effects of such behaviors that contradict with each other. There are also discussions on the ambiguity in the theoretical background. However, the results of the research support the notion substantially that parental control is of two separate constructs which are behavioral and psychological and yield relatively more consistent results when examined by using these constructs (Barber, 1996; Barber, Olsen, \& Shagle, 1994; Kindap, Sayil, \& Kumru, 2008; Sayil \& Kindap, 2010; Steinberg, 1990; Steinberg, Elmen, \& Mounts, 1989). Both of the controlling parentage types could have different effects on the behavioral regulation, the rate of children's obedience to their parents and the type of behavioral problem (Soenens \& Vansteenkiste, 2010). Psychological control is defined as a type of parental control which makes the child depend on his parents emotionally, inhibits child's independence and self-direction ability (Pettit, Bates, Dodge, \& Meece, 2001). Opposite behavioral control is the type of control in which the parents guide their children and show them the appropriate behavior and limit it when necessary (Barber \& Harmon, 2002). 
Psychological control is a parental practice which aims to control a child's inner world experiences often by manipulation strategies (love withdrawal, guilt induction etc.) and are often related to negative results of behaviors (Barber, 1996; 2002; Barber \& Harmon, 2002). Research studies have shown that perceived psychological control is associated with the development of insecure ties between the parent and the child (Doyle \& Markiewicz, 2005; Karavasilis, Doyle, \& Markiewicz, 2003; Kurt, Sayil, \& Kindap Tepe, 2013) and there are findings which indicate that it could be a strong predictor of internal (worry, anxiety, depression, isolation, self-esteem, despair etc.) and external problems (aggression, anti-social behavior, getting involved in a crime) (Barber, 1996; 1999; Barber \& Harmon, 2002; Barber \& Olsen, 1997; Chirkov, 2009; Conger, Conger, \& Scaramella, 1997; Kurt, Sayıl, \& Kındap Tepe, 2013; Loukas, Paulos, \& Robinson, 2005; Soenens, Vansteenkiste, Duriez, \& Goossens, 2006; Soenens, Vansteenkiste, \& Niemiec, 2009). Longitudinal studies provide evidence that psychological control predicts life satisfaction, subjective well-being, increase in physical aggression and these could affect their future lives (Joussemet et al., 2008; Kins, Beyers, Soenens, \& Vansteenkiste, 2009; Kuppens, Grietens, Onghena, \& Michiels, 2009; Saha, Huebner, Suldo, \& Valois, 2010; Wang, Pomerantz, \& Chen, 2007).

Behavioral control, which is used in the sense that parents regulate what their children do, is generally regarded as the opposite of psychological control (Pomerantz \& Wang, 2009). Psychological control is primarily related to negative outcomes, particularly internalization behavior, whereas behavioral control is often associated with positive behavioral and developmental outcomes (Barber, Olsen, \& Shagle, 1994). Observational behavioral control seems to increase positive developmental outcomes on adolescents and decrease negative developmental outcomes (Barber, 1996; Barber, \& Harmon, 2002; Caldwell, Beutler, Ross, \& Silver, 2006; Fletcher, Steinberg, \& Sellers, 1999; Kindap, Sayil, \& Kumru, 2008; Maccoby \& Martin, 1983; Steinberg, Elmen, \& Mounts, 1989). However, it is very important that the level of behavioral control and balance shown here should be established. When this level of control is low, the adolescent tends to take more risks and can make mistakes, while he may feel under pressure and behave improperly when it is high (Barber, Olsen, \& Shagle, 1994; Cui, et al., 2014; Dishion, Capaldi, Spracklen, \& Li, 1995; Manzeske \& Stright, 2009; Pettit, Bates, Dodge, \& Meece, 1999; Stattin \& Kerr, 2000; White \& Kaufman, 1997). Within this context, if the parent can adjust the level of behavioral control in a balanced manner, the adolescent will develop positive behaviors, which will also have a positive impact on intra-family relationships.

It is often seen that controlling parenting practices are related to children's perceiving the environment or the outside world as threatening, unstable and insecure for their future (Gurland \& Grolnick, 2005). Although researchers frequently state that behavioral control leads to positive and psychological control leads to negative behaviors, the level of the control also affects the quality and level of the behavior. Parents' excessive control on the behavior of their children could cause painful emotional experiences such as insecurity, feeling neglected or isolated in their daily lives. At this point, individuals may feel overwhelmed, lose control and face a risk of not being able to gain control again (Heatherton \& Wagner, 2011). The individual may attempt to find alternatives to fill gaps, to reduce adverse effects, or to avoid adversities in such situations. Probably the most popular alternatives are internet technologies which are among the indispensable ones of today's young people who are born in the era of digital technologies and enable the real and virtual lives to be experienced at the same time and spread rapidly every day (Cetinkaya, 2017). Despite the existence of an optimism that every new technology will contribute positively to the lives of individuals, the risk that these technologies can become an isolating factor and cause the individual to be unable to keep the balance between real and virtual worlds should also be considered. In particular, it is possible to claim that internet 
technologies, which become a part of our lives with the inclusion of each new facilitating application to our lives, may have an important share in the spread of this risk. While many researchers have emphasized that the excessive and misuse of these technologies could lead to psychological, behavioral, social and physical adverse effects, attention has also been drawn to the increasing dependence risks towards internet and internet-based applications (ex., Anderson, 2001; Caplan, 2002; Demirer \& Bozoglan, 2015; Derbyshire et al, 2013; Douglas et al., 2008; Lopez-Fernandez et al., 2014; Niemz, Griffiths, \& Banyard, 2005; Poli \& Agrimi, 2012; Young, 1998). As a type of technological dependency (Griffiths, 1999), internet addiction which is defined as impulse control disorder without intoxication (Young, 1998) is increasingly taking part among the major risks of our time. The results of the studies indicate that young people are inclined to create a new and interesting world on the internet, and that they can be open to the risks involved (Cetinkaya \& Sutcu, 2016).

In recent years, social networks, blogs, and similar internet-based applications have become a part of the daily routines of their users, rapidly becoming commonplace in responding to the needs that individuals cannot meet in real life (communication, show up, socialize etc.). Moreover, the attitudes of parents and how these attitudes are perceived by their children are of paramount importance. How the behaviors that the parents think they are doing correctly is perceived by their children and the fact that the internet which the children see as an alternative to avoid the control of their parents may cause different negative effects should also be taken into account.

In particular, it should not be disregarded that the use of internet technologies may become problematic and may even bring about the risks such as addiction. Furthermore, internet technologies are increasingly becoming common at school and young people need to use internet technologies effectively in their education. Therefore, the potential of parents' behaviors to effect young people's use of technologies for educational purposes should not be disregarded. Within this context, the purpose of this study is to examine the relationship between parental psychological and behavioral control perceived by the adolescents and internet addiction. The research questions of the study are as follows:

1. How do the levels of psychological and behavioral control perceived by the adolescents vary according to gender?

2. How are the internet addiction levels of adolescents according to gender?

3. Is there a relationship between internet addiction and the level of psychological control that the adolescents perceived from their parents?

\section{Method}

The study was conducted to determine the possible effects of adolescents psychological and behavioral control perceptions on their internet addiction and was designed in the relational survey model.

\section{Participants}

The sample of the study was formed by using simple random sampling technique which is one of the probability sampling types. 356 students participated in the study at the level of secondary 
education between the ages of $14-18.57 .6 \%$ of the students are female, $42.4 \%$ are male students and their average age is 16 . The participants were informed about the purpose of the study and expectations before the data collection process.

\section{Data Collection Tools}

Psychological Control Scale: Based on the Parental Behavior Inventory (CRPBI) developed by Schaefer (1965), Barber (1996) developed an 8-item Psychological Control Scale. With the scale, calculation of the level of the behaviors of parents which inhibit their children from developing autonomy and expressing himself and interfere with his independence. The developed scale consists of constraining verbal expression, invalidating feelings, personal attack, guilt induction, love withdrawal and erratic emotional behavior (Sayil \& Kindap, 2010). The original 3-point Likert scale was adapted into Turkish culture by Sayil and Kindap (2010) as; characteristics of my mother/father are not like her/him (1) and a lot like her/him (4). Cronbach's Alpha internal consistency coefficient of the main form of the scale consisting of two forms which have the same questions as mother and father changed between .83 and.88 for mother, .83 and.90 for the father (Barber, 1996), while .77 for the mother, .79 for the father in the adaptation into Turkish culture study.

Behavioral Control Scale: The original scale was developed by Brown, Mounts, Lamborn and Steinberg (1993) and was intended to calculate the degree of parental involvement in the regulation and control of their children's behaviors within the framework of family rules and social norms. There are two forms of the questionnaire for the individuals between the ages of 14-19 and they have the same questions for mother and father. The original 3-point Likert scale was adapted into Turkish culture by Kindap, Sayil and Kumru (2008) as; my mother/father never knows (1) and always knows (4). Cronbach's Alpha internal consistency coefficient of the main form of the scale is .81 (Barber, 1996), whereas the mother form was found .75 in the adaptation into Turkish culture.

Internet Addiction Scale (IAS): The Internet addiction scale developed by Young (1998) consists of 20 items, which are collected under four factors: control difficulty, nonfunctionality, social isolation and deprivation. The scale, which is rated between 0 (never) and 5 (always), was adapted by Bayraktar (2001) so that the 12-17 age group adolescents could understand. The Cronbach Alpha internal consistency coefficient of the adapted scale was .91, and SpearmanBrown value was found to be .87 .

Young (1998) defined the adolescents who got a score of 80 and over as "internet addicted", 5079 as "limited symptoms" and 49 points and lower as "No-Symptom".

\section{Data analysis}

During the study, whether the data showed normal distribution or not, the reliability coefficient and the appropriateness of the sample size were also examined. As a result of the analyses detailed in Table 1, the analysis techniques to be applied within the objective of the study were determined. 
Table 1. Descriptive Statistics

\begin{tabular}{lllllllll}
\hline Variables & & N & M & SD & Skewness & Kurtosis & $\begin{array}{l}\text { Cronbach } \\
\text { Alpha }\end{array}$ & KMO \\
& & & & & & & \\
\hline Psychological control & Mother & 356 & 13.07 & 4.61 & -.608 & -.060 & .825 & $.870^{*}$ \\
\hline & Father & 356 & 12.46 & 4.75 & -.344 & -.632 & .837 & $.875^{*}$ \\
\hline Behavioral Control & Mother & 356 & 16.11 & 3.11 & 1.25 & 1.12 & .810 & $.817^{*}$ \\
\hline & Father & 356 & 14.45 & 4.03 & 1.26 & 1.38 & .862 & $.862^{*}$ \\
\hline Internet Addiction & & 356 & 33.53 & 18.76 & .569 & -.408 & .924 & $.929^{*}$ \\
\hline
\end{tabular}

${ }^{*} \mathrm{p}<.01$

As a result of the analyses, it was determined that the internal consistency coefficient of Cronbach Alpha, which indicates the reliability of both measurement tools that measure parental control behaviors, is higher than the original and adaptation studies. These values were calculated as .825 in the mother form of the psychological control scale, .837 in the father form, .810 in the mother form of the behavioral control scale, and .862 in the father form. According to these results, it can be said that psychological control and behavioral control scales have high reliability in both forms for mother and father.

When the Kaiser-Mayer-Olkin (KMO) value, which is used to test the appropriateness of the sample size of the scales, is examined, it is seen that both scales are in the range of .817-.875 and are at a good level. Again, the Cronbach Alpha internal consistency coefficient of the measurement tool developed to measure internet addiction was determined to be .924, and the appropriateness of the sample size (KMO: .929) was found to be almost perfect.

As a result of the analysis processes to test whether the measurement tools used in the study showed normal distribution, it was observed that the arithmetic average, mode and median values were close to each other and kurtosis-skewness coefficients were within the range of $( \pm$ 2.0). In addition to these values, the $Q-Q$ graph was also examined and it was observed that the points on the graph were located on the 45-degree line or within the limits close to this line. Besides the fact that the kurtosis-skewness values are within \pm 2.0 is an acceptable criterion for the normal distribution (George \& Mallery, 2003), it is also supported by Q-Q graph data that the instruments used in the study show normal distribution.

The relationship between the psychological and behavioral control of the adolescents which they perceived from their parents, and the internet addiction was analyzed by correlation and regression analysis. Together with the parental control levels, descriptive statistics related to internet addiction were also included in the study.

\section{Findings}

The analysis results in relation to the distribution of the psychological and behavioral control levels of the adolescents which they perceived from their parents according to their genders are presented in Table 2 . 
Table 2. Psychological and Behavioral Control Levels of Adolescents Which They Perceived from Their Parents by Gender.

\begin{tabular}{|c|c|c|c|c|c|c|c|}
\hline & & & & Mother & & Father & \\
\hline Variable & Gender & & $\mathrm{N}$ & $\mathrm{M}$ & SD & $M$ & SD \\
\hline \multirow{3}{*}{ Psychological control } & Female & & 205 & 12.86 & 4.58 & 12.16 & 4.47 \\
\hline & Male & & 151 & 13.34 & 4.68 & 12.85 & 5.09 \\
\hline & & Total & 356 & 13.07 & 4.61 & 12.46 & 4.75 \\
\hline \multirow{3}{*}{ Behavioral control } & Female & & 205 & 16.86 & 2.71 & 14.53 & 4.06 \\
\hline & Male & & 151 & 15.09 & 3.33 & 14.34 & 3.99 \\
\hline & & Total & 356 & 16.10 & 3.11 & 14.45 & 4.03 \\
\hline
\end{tabular}

Findings show that the level of psychological control perceived by adolescents from their mothers (13.07\%) is higher than that of their fathers (12.46\%). The distribution of psychological control from their parents according to gender of the children has shown that males perceive more psychological control from their parents compared to females. The behavioral control level perceived by the adolescents showed that the behavioral control level they perceived from their mothers $(16.10 \%)$ is higher than that of their fathers (14.45\%). Also, when the distribution of behavioral control is examined in terms of gender of the children, it is seen that females perceive more behavioral control of their mother and father compared to males. When the psychological and behavioral control levels perceived by adolescents were evaluated together, it was determined that both control types of mothers were perceived higher by their children than that of fathers. Moreover, while the males perceive more psychological control from their parents than females, females perceive more behavioral control from their parents compared to males. When the data presented in Table 3 regarding the internet addiction levels of the adolescents are examined, it is seen that the total score of the scale is lower than its average $(M=33.49)$.

Table 3. Internet Addiction Levels of Adolescents in Terms of Gender

\begin{tabular}{|c|c|c|c|c|c|c|c|}
\hline \multirow{4}{*}{ Internet addiction } & Gender & $\mathrm{N}$ & $\mathrm{M}$ & SD & $\mathrm{t}$ & $\mathrm{sd}$ & $\mathrm{P}^{*}$ \\
\hline & Female & 205 & 32.61 & 18.43 & & & \\
\hline & Male & 151 & 34.70 & 19.12 & -1.04 & 354 & .298 \\
\hline & Total & 356 & 33.49 & 18.72 & & & \\
\hline
\end{tabular}

*p<.01; Levene's F=.677, $p>01$

Findings show that males $(M=34.70)$ have higher internet addiction mean scores than females $(M=32.61)$. However, there was no significant relationship between gender variable and Internet addiction ( $t=-1.04, p>.01)$. On the other hand, it was determined that $20.2 \%$ of the students were above the scale total average of 50 and $2 \%$ of the students had a score of 80 or more as Young (1998) defined as "internet addict". The relationship between the psychological and behavioral control perceived by adolescents and internet addiction was examined by Pearson Product Moment Correlation Analysis ( $r$ ). The results are presented in Table 4.

Table 4. Relationship between internet addiction and parental control perceived by adolescents

\begin{tabular}{lccccccccc}
\hline & \multirow{2}{*}{$\mathrm{N}$} & \multicolumn{3}{c}{ Psychological Control } & \multicolumn{3}{c}{ Behavioral Control } \\
\cline { 2 - 10 } Internet addiction & \multicolumn{2}{c}{ Mother } & \multicolumn{2}{c}{ Father } & \multicolumn{2}{c}{ Mother } & \multicolumn{2}{c}{ Father } \\
\cline { 2 - 11 } & \multirow{2}{*}{356} & $\mathrm{r}$ & $\mathrm{p}$ & $\mathrm{r}$ & $\mathrm{p}$ & $\mathrm{r}$ & $\mathrm{p}$ & $\mathrm{r}$ & $\mathrm{p}$ \\
\cline { 3 - 11 } & & $.412^{* *}$ & .000 & $.310^{* *}$ & .000 & -.075 & .155 & -.090 & .089 \\
\hline
\end{tabular}

$* * p<.01$ 
As can be seen In Table 4, there is a statistically significant and positive relationship between internet addiction and psychological control perceived from parents of adolescents, whereas there is a statistically insignificant and negative relationship with perceived behavioral control. In addition, while there was a positive and moderate $(r=.412, p<.01)$ relationship between adolescents' Internet addiction and level of psychological control which children perceived from their mothers, this relationship was found to be positive but weak for fathers $(r=.310, p<.01)$. The regression analysis results of the parents' psychological control levels which predict internet addiction are given in table 5 .

Table 5. Multiple Linear Regression Results Regarding the Adolescents' Perceived Psychological Control's Prediction of Internet Addiction.

\begin{tabular}{|c|c|c|c|c|c|c|c|c|}
\hline Variable & & B & Std. Error & $\beta$ & $\mathrm{t}$ & $p$ & $\begin{array}{c}\text { Dual } \\
r\end{array}$ & $\begin{array}{c}\text { Partial } \\
r\end{array}$ \\
\hline Constant & & 9.763 & 2.919 & & 3.345 & .001 & & \\
\hline \multirow{2}{*}{$\begin{array}{l}\text { Psychological } \\
\text { Control }\end{array}$} & Mother & 1.427 & .242 & .352 & 5.900 & .000 & .412 & .300 \\
\hline & Father & .408 & .235 & .103 & 1.736 & .083 & .310 & .092 \\
\hline
\end{tabular}

$R=421, R^{2}=.177, F_{(2,53)}=37.983, P=.000$

$\mathrm{p}<.01$

When psychological control levels perceived from both parents were evaluated together, it was determined that adolescents' internet addiction had a positive, moderate and significant relationship $(R=.421, R 2=.177, p<.01)$. Furthermore, the analysis results explain about $18 \%$ of the total variance in internet addiction when the psychological controls of the parents are evaluated together. Again, according to the standardized regression coefficient $(\beta)$, it is seen that the psychological control perceived from mother predicts internet addiction at a higher level than that of father. In the light of all the results, it can be said that psychological control perceived from the parents is a significant and positive predictor of the internet addiction level of the adolescents and that psychological control perceived from the mother is more effective in the internet addiction than the psychological control perceived from the father.

The analysis of the relationship between internet addiction and behavioral control perceived from parents yielded that there was a negative and non-significant relationship between adolescents' internet addiction total scores and the behavioral control levels that they perceived from their mothers $(r=-.075, p>.01)$ and fathers $(r=-.090, p>.01)$. In this context, it is observed that the relationship between parental perceived behavioral control and adolescents' internet addiction level is negative but not statistically significant.

\section{Results and Discussion}

This study, which was designed in relational survey model to determine the effects of parental psychological and behavioral control perceived by the adolescents on internet addiction, was conducted with the participation of 356 students aged 14-18. Internet addiction scale was utilized together with the mother and father forms of the measurement instruments which measure the level of psychological and behavioral control perceived by adolescents from their parents. In the study, which employed correlation and regression analysis to determine the effects and direction of the relationship of parental psychological and behavioral control 
perceived by adolescents on internet addiction, descriptive statistics were used. The evaluations of the findings attained from perceived psychological control demonstrated that the levels of psychological control perceived by adolescents from their parents were below the average level.

The results show that adolescents perceive more psychological control from their mothers compared to their fathers. These results show that the level of psychological control that the adolescents receive from their parents is below average and the psychological control perceived from mothers is higher than that of father. Findings of the study are in line with the studies in the literature which suggest that the psychological control perceived from mothers is higher in all adolescents compared to fathers (Barber, Bean, \& Erickson, 2002; Rogers, Buchanan, \& Winchell, 2003; Sayil \& Kindap, 2010;) and males perceive more psychological control than females (Harma, 2008; Kindap, 2011; Kindap \& Sayil, 2012; Shek, 2005; 2007). The analysis of the findings from the perceived behavioral control levels shows that they are above the average. The level of behavioral control that the adolescents perceived from mothers is higher than that of father. Furthermore, it was also found that females perceived higher behavioral control from both their parents compared to males. These results show that adolescents perceive behavioral control above average level from their parents, and the level of behavioral control perceived from mothers is higher than fathers. Moreover, females perceive more behavioral control compared to males. The results are consistent with the findings in the literature which state that behavioral control perceived from fathers are higher than mothers for all adolescents and females more behavioral control than males (Aksoy, Kahraman, \& Kilic, 2008; Kerr \& Stattin, 2000; Kindap, Sayil, \& Kumru, 2008; Smetana \& Daddis, 2002; Soenens, Vansteenkiste, Duriez, \& Goossens, 2006; Sonmez, 2011).

When the findings for Internet addiction were evaluated, it was determined that males had a higher average internet addiction score than females, but there was no significant relationship between gender variable and internet addiction. The results of the analyses show that $20 \%$ of the students were above the scale total value average of 50 and $2 \%$ of the students got the score of 80 or more which Young (1998) defined as "internet addict". Although internet addiction is defined differently in many studies, almost in all of them it is seen as a risk spreading rapidly among internet users, particularly today's youth. It has been reported in the studies that Internet addiction is observed within the rates of $0.7 \%$ and $28 \%$ (Anderson, 2001; Bakken et al., 2009; Cao \& Su, 2007; Dalbudak et al., 2013; Ghassemzadeh, Mehrnaz, \& Alireza, 2008; KaltialaHeino, Lintonen, \& Rimpela, 2004; Ko et.al., 2007; Ni, Yan, Chen, \& Liu, 2009; Pallanti, Bernardi, \& Quercioli, 2006; Park, Kim, \& Cho, 2008; Peterson et.al., 2009; Rumpf et.al., 2014; Siomos et al., 2008; Tsai et.al., 2009; Whang, Lee, \& Chang, 2003; Villella et.al., 2011). This could be due to the variations in the criterion used to define addiction and the measurement instruments together with the method used in the studies (Yellowless \& Marks, 2007).

While there was a positive and statistically significant relationship between Internet addiction and psychological control perceived by adolescents, a statistically insignificant and negative relationship was found with the perceived behavioral control. As a result of the analyses, while it was determined that adolescents' internet addiction total scores correlated positively with the psychological control perceived from mothers and there was a medium level relationship, this relationship was found to be positive but at a lower level with fathers compared to mothers. The findings show that the psychological control perceived from parents is a significant predictor of the internet addiction level statistically in the positive direction and that the psychological control perceived from mother is more effective in the internet addiction than the control perceived from father. Strong evidence is found in the relevant literature that there is a negative relationship between psychological control and the level of adolescents' positive behavior 
development (Barber, 1999; 2001; Barber, Stolz, \& Olsen, 2005; Bronstein, 1994; Dwairy \& Achoui, 2010; Rogers, Buchanan, \& Winchell, 2003; Rudy, Awong, \& Lambert, 2008; Shek, 2007; Shek, Zhu, \& Ma, 2018; Shulman, Collins, \& Dital, 1993; Soenens et al., 2008). Similar results have been obtained in comparative studies with different cultures. In their studies with adolescents from ten different nations, Barber, Stolz and Olsen (2005) found that psychological control predicted both internalization and externalization behavior problems positively and has negative consequences for adolescent functionality. Though the internalization behavior problems have frequently been emphasized in the studies, as Dwairy and Achoui (2010) stated in their study, there is strong evidence that high level of perceived psychological control affects personal adequacy negatively and lead to anxiety and depression. These studies show that perceived psychological control does not affect the outcome behavior of adolescents positively. In this respect, the finding that the level of psychological control perceived by the adolescent increases the risk of internet addiction coincides greatly with the studies in the literature which suggest that the psychological control does not positively affect behavior of the adolescents. When the relationship between internet addiction and behavioral control perceived from parents was examined, it was found that there was a negative and non-significant relationship between adolescent's internet addiction total scores and behavioral control levels perceived from their parents.

While the relationship between the internet addiction levels of the adolescents and the perceived behavioral control is inversely related to the perceived psychological control with no significant relationship, it is found that fathers are more effective than mothers. Findings show that behavioral control perceived from parents effected adolescents' behavior statistically negative without being significant, which also shows that the behavioral control perceived from parents by the individuals has a decreasing effect on the risk of internet addiction. The literature shows that contrary to the psychological control, there is a strong evidence supporting the positive relationship between behavioral control and the level of positive behavior development (Barber, Olsen, \& Shagle, 1994). Behavioral control focused on monitoring, modifying, and controlling the behaviors of adolescents (Nelson \& Crick, 2002) is generally associated with positive emotional-social outcomes (Maccoby \& Martin, 1983). In this respect, the finding that the level of behavioral control perceived by the adolescent influences the internet addiction risk negatively is highly consistent with the results of the studies which suggest that behavioral control affects the adolescents' behaviors positively. However, as pointed out in the study by Stattin and Kerr, (2000), the risk of creating stress in adolescents should not be ignored in cases when behavioral control is highly perceived. At this point, the perception that behavioral control is applied at a high level creates a sense of being over controlled and may lead the behavioral control to gain the qualities of psychological control (Kakihara \& Tilton Weaver, 2009; Kerr, \& Stattin, 2000; Smetana \& Daddis, 2002).

It is often stated in the literature that young people prefer internet environment to escape from the problems of daily life. In the studies, often psychological, social and physical problems which may arise because of the overuse of internet are emphasized adding that either these problems are stimulated or faced with different problems (loss of control, conflict, addiction, isolation, narcissism etc.) while avoiding the problems (loneliness, depression, stress etc.) of the everyday life (Bozoglan, Demirer, \& Sahin, 2014; Caplan, 2002, 2003; Cao et al. 2011; Ceyhan \& Ceyhan, 2008; Derbyshire et al., 2013; Hamburger \& Ben-Artzi, 2003; Kim, LaRose, \& Peng, 2009; Li, Deng, Ren, Guo \& He, 2014; Lopez-Fernandez et al., 2014; Moody, 2001; Ryan \& Xenos, 2011; Spada, 2014; Yeh, Ko, Wu, \& Cheng, 2008; Young, 2004; Young \& Rodgers, 1998). It is often underlined in the literature that the over use of internet to substitute loneliness could lead to depression (Griffiths, 2000; Leung, 2003) or it could lead to increased loneliness and depression (Bessière, 
Kiesler, Kraut, \& Boneva, 2008; Bessière, Pressman, Kiesler, \& Kraut, 2010) and increase the current problems or create new problems. There is also a lot of evidence provided by researchers that parental behavior influences children's internet use habits. (Alvarez et al., 2013; Ang, Chong, Chye, \& Huan, 2012; Ayas \& Horzum, 2013; Chou, \& Lee, 2017; Cevik \& Celikkaleli, 2010; Gunuc \& Dogan, 2013; Khurana, Bleakly, Jordan, \& Romer, 2015; Lam \& Wong, 2015; Lee, \& Chae, 2007; Li, Li, \& Newman, 2013; Valcke, Bonte, De Wever, \& Rots, 2010; Wu et al., 2016; Xiuqin et al., 2010; Young, 2004). At this point since the psychological control involves some methods that can be effective on a child's development via attitudes and acts, and has a multiple and complex structure (Barber et al., 2012), it seems possible for internet addiction to come out. On the other hand, although there are more findings about the positive effects of behavioral control in studies, there are also remarks that it changes to a great extent. In the studies together with the family attitudes, the level of the attitudes was also emphasized. Just as the extreme controller family attitudes could cause risks, families negligent attitudes cause risks too (Cevik, \& Celikkaleli, 2010; Valcke et al., 2010; Young, 1997). Manzesske and Stright (2009) drew attention to this risk and stated that high levels of behavioral and psychological control of parents is associated with inadequate emotional regulation.

All these results show that today's young people may face internet addiction risk and the family could play a role in the occurrence of this risk. One of the most important tasks of parents is to teach their children regulate their emotions, thoughts and behaviors so that they can gain the ability to control themselves (Finkenauer, Engels, \& Baumeister, 2005). In particular, both positive and negative relationships between parents and children are becoming complicated during adolescence (Hafen \& Laursen, 2009) and it should not be overlooked that poor management of family relationships during the period of rapid changes in the family system can negatively affect the future of the child. At this point, the family's efforts to protect their children or their efforts to keep them under control unrestrainedly for any reason, may lead to less information sharing with their parents and cause them to face greater risks (Christakis et al., 2011; Hawk, Keijsers, Hale, \& Meeus, 2009; Cetinkaya \& Sutcu, 2016). As Internet technologies evolve, the individual activities of parents, to protect the individuals from their possible harms, are becoming more important. Hence, parents need to have a balanced behavior towards their children and not lead them to situations which leave them out of their control. In addition, ensuring such a balance could also affect positively young people's use of technology for educational purposes. Furthermore, parents need to have enough knowledge and skill to guide their children, who are born in a world of internet technologies, against the problems of this environment and show them how to act.

\section{Limitations and Implications}

This study presents a theoretical framework and empirical evaluation to explore the effects of behavioral control perceived by adolescents on internet addiction. This study has limitations by default since it offers something new over the existing ones. The first of these limitations is that the study is carried out on adolescents in a Turkish sample, which may limit the generalizability of the results of the study. Future studies may be carried out in different cultures and on a wider sample. The second limitation is that the study examined the relationship between parental control that the students perceived from their parents and internet addiction and evaluations were made by using only the data obtained from adolescents. Parents can also be included in future studies. 
Although there are a lot of studies on the factors that affect the behavior of the individuals in virtual environments, there are quite a lot of unknowns about these environments which offer a different life context. Therefore, the effects of parental control on cyberbullying, victimization, problematic internet use could also be investigated. This study will shed light on future studies on the impact of parental control.

\section{References}

Aksoy, A. B., Kahraman, O. G., \& Kilic, S. (2008). Ebeveynlerin algiladiklari ebeveyn izleme ve destek davranislari [Parental monitoring and support behaviors perceived by adolescents]. Inonu Universitesi Egitim Fakultesi Dergisi, 9(15), 1-14. Retrieved on 22 July 2018 from http://dergipark.gov.tr/download/article-file/92324

Alvarez, M., Torres, A., Rodriguez, E., Padilla, S., \& Rodrigo, M. J. (2013). Attitudes and parenting dimensions in parents' regulation of Internet use by primary and secondary school children. Computers \& Education, 67, 69-78. doi: https://doi.org/10.1016/j. compedu.2013.03.005

Anderson K. J. (2001). Internet use among college students: an exploratory study. Journal of American College Health, 50(1), 21-26. doi: https://doi.org/10.1080/ 07448480109595707

Ang, R. P., Chong, W. H., Chye, S., \& Huan, V. S. (2012). Loneliness and generalized problematic Internet use: Parents' perceived knowledge of adolescents' online activities as a moderator. Computers in Human Behavior, 28(4), 1342-1347. doi: 10.1016/j.chb. 2012.02.019

Austin, E. W. (1990). Effects of family communication on children's interpretation of television. In J. Bryant \& J. A. Bryant (Eds.), Television and the American family (pp. 377-395). Hillsdale, NJ: Lawrence Erlbaum Associates.

Ayas, T. \& Horzum, M. B. (2013). Internet addiction and internet parental style of primary school students. Turkish Psychological Counseling and Guidance Journal, 4(39), 46-57. Retrieved on 20 July 2018 from http://dergipark.gov.tr/download/article-file/200124

Bakken, I. J., Wenzel, H. G., Gotestam, K. G., Johansson, A., \& Oren, A. (2009). Internet addiction among Norwegian adults: A stratified probability sample study. Scandinavian Journal of Psychology, 50(2), 121-127. doi: https://doi.org/10.1111/j.14679450.2008.00685.x

Barber, B. K. (1996). Parental psychological control: Revisiting a neglected construct. Child Development, 67(6), 3296-3319. doi: https://doi.org/10.1111/j.1467-8624.1996. tb01915.x

Barber, B. K. (1999). Political violence, family relations, and Palestinian youth functioning. Journal of Adolescent Research, 14(2), 206-230. doi: https://doi.org/10.1177/ 0743558499142004

Barber, B. K. (2001). Political violence, social, integration, and youth functioning: Palestinian youth from the intifada. Journal of Community Psychology, 29(3), 259-280. doi: https:// doi.org/10.1002/jcop.1017 
Barber, B. K. (2002). Intrusive parenting: How psycho- logical control affects children and adolescents. Washington, DC: American Psychological Association. doi: http://dx.doi. org/10.1037/10422-000

Barber, B. K., Bean, R. L., \& Erickson, L. D. (2002). Expanding the study and understanding of psychological control. In B. K. Barber (Ed.), Intrusive parenting: How psychological control affects children and adolescents (pp. 263-289). Washington DC: American Psychological Association. doi: http://dx.doi.org/10.1037/10422-009

Barber, B. K. \& Harmon, E. L. (2002). Violating the self: Parental psychological control of early adolescents and adolescents. B. K. Barber (Ed.), Intrusive parenting: How psychological control affects children and adolescents (15-52). Washington, DC: American Psychological Association.

Barber, B. K. \& Olsen, J. A. (1997). Socialization in context: Connection, regulation, and autonomy in the family, school, and neighborhood, and with peers. Journal of Adolescent Research, 12(2), 287-315. doi: https://doi.org/10.1177/0743554897122008

Barber, B. K., Olsen, J. E., \& Shagle, S. C. (1994). Associations between parental psychological and behavioral control and youth internalized and externalized behaviors. Child Development, 65(4), 1120-1136. Retrieved on 20 July 2018 from https://www.jstor.org/ stable/1131309

Barber, B. K., Stolz, H. E., \& Olsen, J. A. (2005). Parental support, psychological control, and behavioral control: assessing relevance across time, culture, and method. Monographs of the Society for Research in Child Development, 70(4), 1-13. doi: https://doi.org/ 10.1111/j.1540-5834.2005.00365.x

Barber, B. K., Xia, M., Olsen, J. A., McNeely, C. A., \& Bose, K. (2012). Feeling disrespected by parents: Refining the measurement and understanding of psychological control. Journal of Adolescence, 35(2), 273-287. doi: https://doi.org/10.1016/j.adolescence.2011.10.010

Bayraktar, F. (2001). The role of internet usage in the development of adolescents (Unpublished master's thesis). Ege University, İzmir.

Bessière, K., Kiesler, S., Kraut, R., \& Boneva, B. S. (2008). Effects of internet use and social resources on changes in depression. Information, Communication \& Society, 11(1), 4770. doi: https://doi.org/10.1080/13691180701858851

Bessière, K., Pressman, S., Kiesler, S., \& Kraut, R. (2010). Effects of Internet Use on Health and Depression: A longitudinal study. Journal of Medical Internet Research, 12(1), e6. doi: https://doi.org/10.2196/jmir.1149

Bozoglan, B. Demirer, V. \& Sahin, I. (2014). Problematic Internet use: Functions of use, cognitive absorption, and depression. Computers in Human Behavior, 37, 117-123. doi: https://doi.org/10.1016/j.chb.2014.04.042

Bronstein, P. (1994). Patterns of Parent-Child Interaction in Mexican Families: A Cross-cultural Perspective. International Journal of Behavioral Development, 17(3), 423-446. doi: https://doi.org/10.1177/016502549401700303

Brown, B. B., Mounts, N., Lamborn, S. D., \& Steinberg, L. (1993). Parenting practices and peer group affiliation in adolescence. Child Development, 64(2), 467-482. doi: https://doi.org/ 10.1111/j.1467-8624.1993.tb02922.x 
Caldwell, R. M., Beutler, L. E., Ross, S. A., \& Silver, N. C. (2006). Brief report: An examination of the relationships between parental monitoring, self-esteem and delinquency among Mexican American male adolescents. Journal of Adolescence, 29(3), 459-464. doi: https: //doi.org/10.1016/j.adolescence.2005.07.005

Cao, F. \& Su, L. (2006). Internet addiction among Chinese adolescents: prevalence and psychological features. Child: Care, Health and Development, 33(3), 275-281. doi: https: //doi.org/10.1111/j.1365-2214.2006.00715.x

Cao, H., Sun, Y., Wan, Y., Hao, J., \& Tao, F. (2011) Problematic Internet use in Chinese adolescents and its relation to psychosomatic symptoms and life satisfaction. $B M C$ Public Health, 11(1), 802-810 doi: https://doi.org/10.1186/1471-2458-11-802

Caplan, S. E. (2002). Problematic Internet use and psychosocial well-being: Development of a theory based cognitive-behavioral measurement instrument. Computers in Human Behavior, 18, 553-575.

Caplan, S. E. (2003). Preference for online social interaction: A theory of problematic Internet use and psychosocial well-being. Communication Research, 30(6), 625-648. doi: https:// doi.org/10.1177/0093650203257842

Cetinkaya, L. (2017). An educational technology tool that developed in the natural flow of life among students: WhatsApp. International Journal of Progressive Education, 13(2), 29-47. Retrieved on 11 July 2018 from http://files.eric.ed.gov/fulltext/EJ1145590.pdf

Cetinkaya, L. \& Sutcu, S. S. (2016). Parents' Restrictions on Their Children's Use of Information Technologies and Their Reasons. Turkish Online Journal of Qualitative Inquiry, 7(1), 1836. doi: http://dx.doi.org/10.17569/tojqi.58102

Ceyhan, A. A. \& Ceyhan, E. (2008). Loneliness, depression, and computer self-efficacy as predictors of problematic internet use. CyberPsychology and Behavior, 11(6), 699-701. doi: https://doi.org/10.1089/cpb.2007.0255

Chirkov, V. I. (2009). A cross cultural analysis of autonomy in education: A self determination theory perspective. Theory and Research in Education, 7(2), 253-262. doi: https://doi. org/10.1177/1477878509104330

Chou, C. \& Lee Y. H. (2017). The Moderating Effects of Internet Parenting Styles on the Relationship between Internet Parenting Behavior, Internet Expectancy, and Internet Addiction Tendency. The Asia-Pacific Education Researcher, 26(3-4), 137-146. doi: https://doi.org/10.1007/s40299-017-0334-5

Christakis, D. A., Moreno, M. M., Jelenchick, L., Myaing, M. T., \& Zhou, C. (2011). Problematic internet usage in US college students: a pilot study. BMC Medicine, 9(77). doi: https:// doi.org/10.1186/1741-7015-9-77

Conger, K. J., Conger, R. D., \& Scaramella, L. V. (1997). Parents, siblings, psychological control, and adolescent adjustment. Journal of Adolescent Research, 12(1), 113-138. doi: https: //doi.org/10.1177/0743554897121007

Cui, L., Morris, A.S., Criss, M.M., Houltberg, B.J., \& Silk, J.S. (2014). Parental psychological control and adolescent adjustment: The role of adolescent emotion regulation. Parenting: Science and Practice, 14(1), 47-67. doi: https://doi.org/10.1080/15295192. 2014.880018

Cevik, B. G. \& Celikkaleli, O. (2010). Ergenlerin arkadas bagliligi ve internet bagimliliginin cinsiyet, ebeveyn tutumu ve anne baba egitim duzeylerine gore incelenmesi 
[Adolescent' friends attachment and internet addiction according to gender, perception parents attitudes and parents educational levels]. Cukurova Universitesi Sosyal Bilimler Enstitusu Dergisi, 19(3), 225-240. Retrieved on 11 July 2018 from http://dergipark. ulakbim.gov.tr/ cusosbil/article/view/5000001458/5000002149

Dalbudak, E., Evren, C., Aldemir, S., Coskun, K. S., Ugurlu, H., \& Yildirim, F. G. (2013) Relationship of internet addiction severity with depression, anxiety, and alexithymia, temperament and character in university students. Cyberpsychology, Behavior, and Social Networking, 16(4), 272-278. doi: https://doi.org/10.1089/cyber.2012.0390

Demirer, V. \& Bozoglan, B. (2015). Purposes of Internet use and problematic Internet use among Turkish high school students. Asia-Pacific Psychiatry, 8(4), 269-277. doi: https:// doi.org/ 10.1111/appy.12219

Derbyshire, K. L., Lust, K. A., Schreiber, L. R., Odlaug, B. L., Christenson, G. A., Golden, D. J., \& Grant, J. E. (2013). Problematic Internet use and associated risks in a college sample. Comprehensive psychiatry, 54(5), 415-422. Doi: 10.1016/j.comppsych.2012.11.003

Dishion, T. J., Capaldi, D., Spracklen, K. M., \& li, F. (1995). Peer ecology of male adolescent drug use. Development and Psychopathology, 7(4), 803-824. doi: https://doi.org/10.1017/ S0954579400006854

Douglas, A. C., Mills, J., Niang, M., Stepchenkova, S., Byun, S., Ruffini, C., Lee, S. K. Loutfi, J., Lee, J-K., Atallah, M., \& Blanton, M. (2008). Internet addiction: Meta-synthesis of qualitative research for the decade 1996 - 2006. Computers in Human Behavior, 24(6), 3027-3044. doi: https://doi.org/10.1016/j.chb.2008.05.009

Doyle, A. B. \& Markiewicz, D. (2005). Parenting, marital conflict, and adjustment, from early to mid adolescence: Mediated by adolescent attachment style? Journal of Youth and Adolescence, 34(2), 97-110. doi: http://dx.doi.org/10.1007/s10964-005-3209-7

Dwairy, M. \& Achoui, M. (2010.) Parental control: a second cross- cultural research on parenting and psychological adjustment of children. Journal of Child and Family Studies, 19(1), 16-22. doi: https://doi.org/10.1007/s10826-009-9334-2

Finkenauer C, Engels R. C. M. E., \& Baumeister R. F. (2005). Parenting behavior and adolescent behavioral emotional problems: the role of self-control. International Journal of Behavioral Development, 29(1), 58-69. doi: https://doi.org/10.1080/ 01650250444000333

Fletcher, A. C., Steinberg, L., \& Williams-Wheeler, M. (2004). Parental Influences on Adolescent Problem Behavior: Revisiting Stattin \& Kerr. Child Development, 75(3), 781-796. doi: 10.1111/j.1467-8624.2004.00706.x

George, D. \& Mallery, P. (2003). SPSS for Windows step by step: A simple guide and reference 11.0 update (4th ed.). Boston: Pearson Education.

Ghassemzadeh, L., Mehrnaz, S., \& Alireza, M. (2008). Prevalence of Internet addiction and comparison of Internet addicts and non-addicts in Iranian high schools. CyberPsychology \& Behavior, 11(6), 731-733. doi: https://doi.org/10.1089/cpb.2007.0243

Griffiths, M. D. (1999). Internet addiction. The Psychologist, 12(5), 246-251. Retrieved on 11 July 2018 from https://thepsychologist.bps.org.uk/getfile/3118

Griffiths, M. D. (2000). Does Internet and computer "addiction" exist? Some case study evidence. CyberPsychology \& Behavior, 3(2), 211-218. doi: https://doi.org/10.1089/ 109493100316067 
Gurland, S. T. \& Grolnick, W. S. (2005). Perceived threat, controlling parenting and children's achievement orientations. Motivation and Emotion, 29(2), 103-121. doi: http://dx.doi. org/10.1007/s11031-005-7956-2

Gunuc, S. \& Dogan, A. (2013). The relationships between Turkish adolescents' Internet addiction, their perceived social support and family activities. Computers in Human Behavior, 29(6), 2197-2207. doi: https://doi.org/10.1016/j.chb.2013.04.011

Hafen, C. A. \& Laursen, B. (2009). More problems and less support: Early adolescent adjustment forecasts changes in perceived support from parents. Journal of Family Psychology, 23(2), 193-202. doi: https://doi.org/10.1037/a0015077

Hamburger, Y. A., \& Ben-Artzi E. (2003). Loneliness and Internet use. Computers in Human Behavior, 19(1), 71-80. doi: https://doi.org/10.1016/S0747-5632(02)00014-6

Harma, M. (2008). The impact of parental control and marital conflict on adolescents' selfregulation and adjustment (Unpublished master's thesis). Middle East Technical University, Ankara.

Hawk, S. T., Keijsers, L. Hale, W, \& Meeus, W. (2009). Mind your own business! Longitudinal relations between perceived privacy invasion and adolescent-parent conflict. Journal of Family Psychology, 23(4), 511-520. doi: https://doi.org/10.1037/a0015426

Heatherton, T. F. \& Wagner, D. O. (2011). Cognitive Neuroscience of Self-Regulation Failure. Trends in Cognitive Sciences, 15(3), 132-139. doi: https://dx.doi.org/10.1016\%2Fj. tics.2010.12.005

Joussemet, M., Vitaro, F., Barker, E. D., Cote, S., Nagin, D. S., \& Tremblay, R. (2008). Controlling parenting and physical aggression during elementary school. Child Development, 79(2), 411-425. doi: https://doi.org/10.1111/j.1467-8624.2007.01133.x

Kakihara, F., \& Tilton Weaver, L. (2009). Adolescents' interpretations of parental control: Differentiated by domain and types of control. Child Development, 80(6), 1722-1738. doi: https://doi.org/10.1111/j.1467-8624.2009.01364.x

Kaltiala-Heino, R., Lintonen, T., \& Rimpela A. (2004). Internet addiction? Potentially problematic use of the Internet in a population of 12-18-year-old adolescents. Addiction Research \& Theory, 12(1), 89-96. doi: http://dx.doi.org/10.1080/1606635031000098796

Karavasilis, L., Doyle, A. B., \& Markiewicz, D. (2003). Associations between parenting style and attachment to mother in middle childhood and adolescence. International Journal of Behavioral Development, 27(2), 153-164. doi: https://doi.org/10.1080/ 0165025024400015

Kerr, M. \& Stattin, H. (2000). What parents know, how they know it and several forms of adolescent adjustment: Further support for a reinterpretation of monitoring? Developmental Psychology, 36(3), 366-380. doi: http://dx.doi.org/10.1037/00121649.36.3.366

Khurana, A., Bleakly, A., Jordan, A. B., \& Romer, D. (2015). The Protective Effects of Parental Monitoring and Internet Restriction on Adolescents' Risk of Online Harassment. Journal of Youth and Adolescence, 44(5), 1039-1047. doi: https://doi.org/10.1007/s10964-0140242-4

Kındap, Y. (2011). A longitudinal study of the relationship between supportive parenting, social adjustment and self determination level among adolescents on the basis of self determination theory (Unpublished doctoral dissertation). Hacettepe University, Ankara. 
Kindap, Y. \& Sayil, M. (2012). The Mediating Role of Relational Aggression in the Relationship between Parental Control and Social Functioning of the Adolescent. Turkish Journal of Psychology, 27(70), 119-132. Retrieved on 11 July 2018 from https://www.tedu.edu.tr/ sites/default/files/content_files/research_files/kindap_tepe_sayil_2012_0.pdf

Kindap, Y., Sayil, M., \& Kumru, A. (2008). The relationships among type of perceived maternal control, psychosocial adjustment, and friendship in adolescence: The mediator role of self-esteem. Turkish Journal of Psychology, 23(61), 92-107. Retrieved on 11 July 2018 from http://www.turkpsikolojiyazilari.com/PDF/TPD/61/92-107.pdf

Kim, J., LaRose, R., \& Peng, W. (2009). Loneliness as the cause and the effect of problematic Internet use: The relationship between Internet use and psychological well-being. CyberPsychology \& Behavior, 12(4), 451-455. doi: https://doi.org/10.1089/cpb. 2008.0327

Kins, E., Beyers, W., Soenens, B., \& Vansteenkiste, M. (2009). Patterns of home leaving and subjective well-being in emerging adulthood: The role of motivational processes and parental autonomy support. Developmental Psychology, 45(5), 1416-1429. doi: https://doi.org/10.1037/a0015580

Ko, C-H., Yen, J-Y., Yen, C-F., Lin, H-C., \& Yang, M-J. (2007). Factors predictive for incidence and remission of internet addiction in young adolescents: a prospective study. CyberPsychology \& Behavior, 10(4): 545-551. doi: https://doi.org/10.1089/cpb.2007. 9992

Kuppens, S., Grietens, H., Onghena, P., \& Michiels, D. (2009). Relations between parental psychological control and childhood relational aggression: Reciprocal in nature? Journal of Clinical Child \& Adolescent Psychology, 38(1), 117-131. doi: https://doi.org/10.1080/ 15374410802575354

Kurt, D., Sayil, M., \& Kindap Tepe, Y. (2013). Summary the Relation between Parental Psychological Control and Late Adolescents' Loneliness: The Mediator Roles of Interpersonal Trust and Attachment. Turkish Journal of Psychology, 28(71), 105-116. Retrieved on 11 July 2018 from http://www.turkpsikolojiyazilari.com/PDF/TPD/71/07. pdf

Lam, L. T. \& Wong, E. M. (2015). Stress moderates the relationship between problematic Internet use by parents and problematic Internet use by adolescents. Journal of Adolescent Health, 56(3), 300-306. doi: 10.1016/j.jadohealth.2014.10.263

Lee, S. J. \& Chae, Y. G. (2007). Children's Internet use in a family context: Influence on family relationships and parental mediation. CyberPsychology \& Behavior, 10(5), 640-644. doi: https://doi.org/10.1089/cpb.2007.9975

Leung, L. (2003). Impacts of Net-generation attributes, seductive properties of the Internet, and gratifications-obtained on Internet use. Telematics and Informatics, 20(2), 107-129. doi: https://doi.org/10.1016/S0736-5853(02)00019-9

Li, M., Deng, Y., Ren., Y., Guo, S., \& He, X. (2014). Obesity status of middle school students in Xiangtan and its relationship with Internet addiction. Obesity, 22(2), 482-487. doi: https: //doi.org/10.1002/oby.20595

Li, X., Li, D., \& Newman, J. (2013). Parental behavioral and psychological control and problematic Internet use among Chinese adolescents: The mediating role of self-control. Cyberpsychology, Behavior, and Social Networking, 16(6), 442-447. doi: https://doi.org/ 10.1089/cyber.2012.0293 
Lopez-Fernandez, O., Honrubia-Serrano, M. L., Gibson, W., \& Griffiths, M. D. (2014). Problematic Internet use in British adolescents: An exploration of the addictive symptomatology. Computers in Human Behavior, 35, 224-233. doi: https://doi.org/ 10.1016/j.chb.2014.02.042

Loukas, A., Paulos, S. K., \& Robinson, S. (2005). Early adolescent social and overt aggression: Examining the roles of social anxiety and maternal psychological control. Journal of Youth and Adolescence, 34(4), 335-226. doi: https://doi.org/10.1007/s10964-005-5757-2

Maccoby, E. E. \& Martin, J. (1983). Socialization in the context of the family: Parent-child interaction. P. H. Mussen \& E. M. Hetherington in Handbook of child psychology: Vol 4. Socialization, personality, and social development, (1-101). New York: Wiley.

Manzeske, D. P. \& Stright A. (2009). Parenting styles and emotion regulation: The role of behavioral and psychological control during young adulthood. Journal of Adult Development, 16(4), 223-229. doi: https://doi.org/10.1007/s10804-009-9068-9

Moody, E. J. (2001). Internet use and its relationship to loneliness. CyberPsychology \& Behavior, 4(3), 393-401. doi: https://doi.org/10.1089/109493101300210303

Nelson, D. A. \& Crick, N. R. (2002). Parental psychological control: Implications for childhood physical and relational aggression. In B. K. Barber (Ed.), Intrusive parenting: How psychological control affects children and adolescents (pp. 161-189). Washington, DC: American Psychological Association.

$\mathrm{Ni}, \mathrm{X}$., Yan, H., Chen, S., \& Liu, Z. (2009). Factors influencing internet addiction in a sample of freshmen university students in China. CyberPsychology \& Behavior, 12(3), 327-330. doi: https://doi.org/10.1089/cpb.2008.0321

Niemz, K., Griffiths, M., \& Banyard, P. (2005). Prevalence of pathological Internet use among university students and correlations with self-esteem, the General Health Questionnaire (GHQ), and disinhibition. Cyberpsychology and Behavior, 8(6), 562-570. doi: https://doi. org/10.1089/cpb.2005.8.562

Pallanti, S., Bernardi, S., \& Quercioli, L. (2006). The Shorter PROMIS Questionnaire and the Internet Addiction Scale in the assessment of multiple addictions in a high-school population: prevalence and related disability. CNS Spectrums, 11(12), 966-974. doi: https://doi.org/10.1017/S1092852900015157

Park, S. K., Kim, J. Y., \& Cho, C. B. (2008). Prevalence of Internet addiction and correlations with family factors among South Korean adolescents. Adolescence, 43(172), 895-909. Retrieved on 11 July 2018 from https://www.ncbi.nlm.nih.gov/pubmed/19149152

Peterson, K. U., Weymann, N., Schelb, Y., Thiel, R., \& Thomasius, R. (2009) Pathological Internet use--epidemiology, diagnostics, co-occurring disorders and treatment. Fortschritte der Neurologie-Psychiatrie, 77(5), 263-271. doi: https://doi.org/10.1055/s0028-1109361

Pettit, G. S., Bates, J. E., Dodge, K. A., \& Meece, D. W. (1999). The impact of after-school peer contact on early adolescent externalizing problems is moderated by parental monitoring, perceived neighborhood safety, and prior adjustment. Child Development, 70(3), 768-778. doi: https://doi.org/10.1111/1467-8624.00055

Poli, R. \& Agrimi, E. (2012). Internet addiction disorder: prevalence in an Italian student population. Nordic Journal of Psychiatry, 66(1), 55-59. doi: https://doi.org/10.3109/ 08039488.2011.605169 
Pomerantz, E. M. \& Wang, Q. (2009). The role of parental control in children's development in Western and East Asian countries. Current Directions in Psychological Science, 18(5), 285. https://doi.org/10.1111/j.1467-8721.2009.01653.x

Rogers, K. N., Buchanan, C. M., \& Winchell, M. E. (2003). Psychological control during early adolescence: Links to adjustment in differing parent/adolescent dyads. Journal of Early Adolescence, 23(4), 349-383. doi: https://doi.org/10.1177/0272431603258344

Rudy, D., Awong, T., \& Lambert, M. (2008). Parental psychological control and authoritarianism in Chinese-Canadian and European-Canadian cultural groups: Their meanings and implications for university students' adjustment. Journal of Comparative Family Studies, 39(4), 471-490. Retrieved on 11 July 2018 from https://www.jstor.org/stable/41604241

Rumpf, H. J., Vermulst A. A, Bischof, A., Kastirke, N., Gurtler, D., Bischof, G., \& Meerkerk, G.-J., John U., \& Meyer C. (2013). Occurrence of internet addiction in a general population sample: a latent class analysis, European addiction research, 20(4), 159-166. doi: https://doi.org/10.1159/000354321

Ryan, T. \& Xenos, S. (2011). Who uses Facebook? An investigation into the relationship between the Big Five, shyness, narcissism, loneliness, and Facebook usage. Computers in Human Behavior, 27(5), 1658-1664. doi: https://doi.org/10.1016/j.chb.2011.02.004

Saha, R., Huebner, E. C., Suldo, S. M., \& Valois, R. F. (2010). A longitudinal study of adolescent life satisfaction and parenting. Child Indicators Research, 3(2), 149-165. doi: http://dx. doi.org/10.1007/s12187-009-9050-x

Sayil, M., \& Kindap, Y. (2010). Turkish adaptation of the parental psychological control scale(s): A study of validity and reliability. Turkish Psychological Articles, 13(25), 62-71. Retrieved on 11 July 2018 from http://www.turkpsikolojiyazilari.com/PDF/TPY/25/05.pdf

Schaefer, E. W. (1965). Children's reports of parental behavior: An inventory. Child Development, 36(2), 413-424. doi: http://dx.doi.org/10.2307/1126465

Shek, D. T. L. (2005). Perceived parental control and parent-child relational qualities in Chinese adolescents in Hong Kong. Sex Roles, 53(9-10), 635-646. doi: http://dx.doi.org/10.1007/ s11199-005-7730-7

Shek, D. T. L. (2007). A longitudinal study of perceived differences in parental control and parent-child relational qualities in Chinese adolescents in Hong Kong. Journal of Adolescent Research, 22(2), 156-188. doi: https://doi.org/10.1177/0743558406297509

Shek, D. T. L., Zhu, X., \& Ma, C. M. S. (2018). The influence of parental control and parent-child relational qualities on adolescent internet addiction: A 3-year longitudinal study in Hong Kong. Frontiers in Psychology, 9, 642. doi: https://doi.org/10.3389/fpsyg.2018. 00642

Shulman, S., Collins, W. A., \& Dital, M. (1993). Parent-child relationships and peer-perceived competence during middle childhood and preadolescence in Israel. Journal of Early Adolescence, 13(2), 204-218. doi: https://doi.org/10.1177/0272431693013002005

Siomos, K. E., Dafouli, E. D., Braimiotis, D.A., Mouzas, O. D., \& Angelopoulos, N. V. (2008). Internet addiction among Greek adolescent students. CyberPsychology \& Behavior, 11(6), 653-657. doi: https://doi.org/10.1089/cpb.2008.0088

Smetana, J. G. \& Daddis, C. (2002). Domain-specific antecedents of psychological control and parental monitoring: The role of parenting beliefs and practices. Child Development, 73(2), 563-580. doi: https://doi.org/10.1111/1467-8624.00424 
Soenens, B. \& Vansteenkiste, M. (2010). A theoretical upgrade of the concept of parental psychological control: Proposing new insights on the basis of self-determination theory. Developmental Review, 30(1), 74-99. doi: https://doi.org/10.1016/j.dr.2009.11.001

Soenens B., Vansteenkiste, M., Duriez, B., \& Goossens, L. (2006). In search of the sources psychologically controlling parenting: the role of parental separation anxiety and parental maladaptive perfectionism. Journal of Research on Adolescence, 16(4), 539-559. doi: https://doi.org/10.1111/j.1532-7795.2006.00507.x

Soenens, B., Vansteenkiste M., \& Niemiec, C. P. (2009). Should parental prohibition of adolescents' peer relationships be prohibited? Personal Relationships, 16(4), 507- 530. doi: https://doi.org/10.1111/j.1475-6811.2009.01237.x

Soenens, B., Vansteenkiste, M., Goossens, L., Duriez, B., \& Niemiec, C. P. (2008). The Intervening role of relational aggression between psychological control and friendship quality. Social Development, 17(3), 661-681. doi: https://doi.org/10.1111/j.14679507.2007.00454.x

Sonmez, S. (2011). The role of mother's behavioral and psychological control both on the mother-adolescent relationship and the adolescent's a year later adjustment during transition to adolescence (Unpublished master's thesis). Hacettepe University, Ankara.

Spada, M. M. (2014). An overview of problematic Internet use. Addictive behaviors, 39(1), 3-6. doi: https://doi.org/10.1016/j.addbeh.2013.09.007

Stattin, H. \& Kerr, M. (2000). Parental monitoring: A reinterpretation. Child Development, 71(4), 1072-1085. doi: https://doi.org/10.1111/1467-8624.00210

Steinberg, L. (1990). Autonomy, conflict, and harmony in the family relationship. In S. S. Feldman \& G. R. Elliott (Eds.), At the threshold: The developing adolescent (pp. 255-276). Cambridge, MA, US: Harvard University Press.

Steinberg, L., Elmen, J. D., \& Mounts, N. S. (1989). Authoritative parenting, psychosocial maturity, and academic success among adolescents. Child Development, 60(6), 14241436. doi: http://dx.doi.org/10.2307/1130932

Tsai, H. F., Cheng, S. H., Yeh, T.L., Shih, C. C., Chen, K. C., Yang, Y. C., \& Yang, Y. K., (2009). The risk factors of Internet addiction-A survey of university freshmen. Psychiatry Research, 167(3), 294-299. doi: https://doi.org/10.1016/j.psychres.2008.01.015

Valcke, M., Bonte, S., De Wever, B., \& Rots, I. (2010). Internet parenting styles and the impact on Internet use of primary school children. Computers and Education, 55(2), 454-464. doi: https://doi.org/10.1016/j.compedu.2010.02.009

Villella, C., Martinotti, G., Di Nicola, M., Cassano, M., La Torre, G., Gliubizzi, M. D., Messeri, I., Petruccelli, F., Bria, P., Janiri, L., \& Conte, G. (2011). Behavioral addictions in adolescents and young adults: results from a prevalence study. Journal of Gambling Studies, 27(2), 203-214. doi https://doi.org/10.1007/s10899-010-9206-0

Wang, Q., Pomerantz, E. M., \& Chen, H. (2007). The role of parents control in early adolescents' psychological functioning: A longitudinal investigation in the United States and China. Child Development, 78(5), 1592-1610. doi: https://doi.org/10.1111/j.14678624.2007.01085.x

Whang, L. S., Lee, S., Chang, G. (2003). Internet over-users' psychological profiles: A behavior sampling analysis on internet addiction. CyberPsychology \& Behavior, 6(2), 143-150. doi: https://doi.org/10.1089/109493103321640338 
White, M. J. \& Kaufman, G. (1997). Language usage, social capital, and school completion among immigrants and native-born ethnic groups. Social Science Quarterly, 78(2), 385398. Retrieved on 11 July 2018 from https://www.jstor.org/stable/42864344

Wu, C. S. T., Wong, H. T., Yu, K. F., Fok, K. W., Yeung, S. M., Lam, C. H., \& Liu, K. M. (2016). Parenting approaches, family functionality, and internet addiction among Hong Kong adolescents. BMC Pediatrics, 16(1), 130. doi: https://doi.org/10.1186/s12887-016-0666y

Xiuqin, H., Huimin, Z, Mengchen, L., Jinan, W., Ying, Z., \& Ran, T. (2010). Mental health, personality, and parental rearing styles of adolescents with internet addiction disorder. Cyberpsychology, Behavior, and Social Networking, 13(4), 401-406. doi: https://doi.org/ 10.1089/cyber.2009.0222

Yeh, Y. C., Ko, H. C., Wu, J. Y. W., \& Cheng, C. P. (2008). Gender differences in relationships of actual and virtual social support to internet addiction mediated through depressive symptoms among college students in Taiwan. CyberPsychology \& Behavior, 11(4), 485487. Doi: https://doi.org/10.1089/cpb.2007.0134

Yellowlees, P. M. \& Marks, S. (2007). Problematic internet use or internet addiction? Computers in Human Behavior, 23(3), 1447-1453. doi: https://doi.org/10.1016/j.chb. 2005.05.004

Young, K. S. (1997). What makes the internet addictive: potential explanations for pathological internet use? $105^{\text {th }}$ Annual Conference of the American Psychological Association. Chicago, IL.

Young, K. S. (1998). Internet addiction: The emergence of a new clinical disorder. CyberPsychology \& Behavior, 3(1), 237-244. doi: http://doi.org/10.1089/cpb.1998.1.237

Young, K. S. (2004). Internet addiction: A new clinical phenomenon and its consequences. The American Behavioral Scientist, 48(4), 402-415. doi: https://doi.org/10.1177/ 0002764204270278

Young, K. S. \& Rodgers, R. C. (1998). The relationship between depression and Internet addiction. Cyberpsychology, Behavior, and Social Networking, 1(1), 25-28.

https://doi.org/10.1089/cpb.1998.1.25

Correspondence: Levent Cetinkaya, Assistant Professor, Department of Computer Education and Instructional Technology, Faculty of Education, Canakkale Onsekiz Mart University, Canakkale, Turkey 